\title{
Uterine Fibroid Symptom and Health-related Quality of Life Questionnaire: a Chinese translation and validation study
}

\author{
SY Yeung *, Janice WK Kwok, SM Law, Jacqueline PW Chung, Symphorosa SC Chan
}

This article was published on 4 Dec 2019 at www.hkmj.org.

\section{A B S T R A C T}

Introduction: The Uterine Fibroid Symptom and Health-related Quality of Life (UFS-QOL) questionnaire is a validated tool in English language to assess treatment outcomes for women with fibroids. We performed a Chinese (traditional) translation and cultural adaptation of it and evaluated its reliability, validity, and responsiveness.

Methods: Overall, 223 Chinese women aged $\geq 18$ years with uterine fibroids self-administered the UFS-QOL, Short-Form Health Survey-12, pictorial blood loss assessment chart (PBAC), and a visual analogue scale (VAS) on fibroid-related symptom severity. Demographics and haemoglobin levels were recorded; physical examination and ultrasound for size of fibroids were performed. Half of the women were followed up 6 months later for responsiveness.

Results: Cronbach's alpha coefficients ranged from 0.706 to 0.937 , demonstrating high internal reliability. The intra-class correlation coefficients to measure test-retest reliability implied excellent stability of symptom scores $(0.819, \mathrm{P}<0.001)$, healthrelated quality of life scores $(0.897, \mathrm{P}<0.001)$, and all subscales (range 0.721-0.870, $\mathrm{P}<0.001$ ). Convergent validity was demonstrated by positive correlations between the findings of various symptom severity assessment tools (PBAC, VAS on fibroid-related symptoms severity) and the symptom severity domain of Chinese UFS-QOL. In addition, there were positive correlations between health-related quality of life scores of Chinese UFS-QOL and the corresponding subscales of the Short-Form Health Survey-12. Responsiveness was shown by reduction of symptom severity scores and improvement of health-related quality of life scores after treatment.

Conclusions: The Chinese version of the UFS-QOL is valid, reliable, and responsive to changes after treatment.

\section{Hong Kong Med J 2019;25:453-9

https://doi.org/10.12809/hkmj198064

SY Yeung *, FHKAM (Obstetrics and Gynaecology), FHKCOG

JWK Kwok, BSc

SM Law, FHKAM (Obstetrics and Gynaecology), FHKCOG

JPW Chung, FHKAM (Obstetrics and Gynaecology), FHKCOG

SSC Chan, FHKAM (Obstetrics and Gynaecology), FHKCOG

Department of Obstetrics and Gynaecology, Prince of Wales Hospital, The Chinese University of Hong Kong, Shatin, Hong Kong

* Corresponding author: carolyeung@cuhk.edu.hk

New knowledge added by this study

- The Chinese version of the Uterine Fibroid Symptom and Quality of Life Questionnaire (UFS-QOL) questionnaire is a valid and reliable tool to assess the impact of uterine fibroids on women's quality of life, and it can be used to evaluate the response after treatment for uterine fibroids.

Implications for clinical practice or policy

- The Chinese version of the UFS-QOL questionnaire can be used to evaluate the impact of uterine fibroids on quality of life to guide treatment and evaluate response during daily clinical practice. It is also a useful research tool to assess quality of life improvements after various fibroid treatments.

\section{Introduction}

Fibroids are the most common benign uterine tumour affecting reproductive age women, and the lifetime risk is up to $60 \%$ in women aged over 45 years. ${ }^{1,2}$ They are associated with menorrhagia, ${ }^{3,4}$ which results in anaemia and reduced vitality. ${ }^{5}$ They also exert mass effects, leading to significantly increased urinary frequency and stress urinary incontinence compared with the general population. ${ }^{6}$ Moreover, women with fibroids may experience deep dyspareunia. ${ }^{7}$ All the above have negative effects on quality of life.

Measuring the symptoms and quality of life of women with fibroids is important, as it is a major indicator for treatment. The Uterine Fibroid Symptom and Health-related Quality of Life Questionnaire (UFS-QOL) is an English questionnaire published in 2002 that was specially designed to assess the whole spectrum of fibroid-related symptoms and its impact on quality of life. ${ }^{8}$ It consists of eight items on symptoms and 29 on health-related quality of life (HRQL) with six subscales (concern, activities, energy/mood, control, self-consciousness, and sexual functioning). A raw score ranging from 1 to 5 is assigned to each of the items. To calculate the 


\section{子宮肌瘤病徵及生活素質問卷（UFS-QOL）： 中文譯本和驗證 \\ 楊雪瑩、郭藴琪、羅思敏、鍾佩樺、陳丞智}

引言：子宮肌瘤病徵及生活素質問卷（UFS-QOL）是經過驗證的英 語問卷, 用於評估患有子宮肌瘤女性的治療效果。我們對其進行中文 （繁體）翻譯和文化改編，並評估其可靠性、有效性和反應性。

方法：共223名 18 歲或以上患有子宮肌瘤的中國婦女參與研究。她們 完成繁體中文版本的UFS-QOL、12型簡短健康調查、經血量評估表

（PBAC）以及有關肌瘤相關症狀嚴重程度的視覺模擬量表（VAS）

後, 由婦科醫生進行檢查和以超聲檢查肌瘤的大小及檢驗血紅蛋白水

平。其中一半婦女於6個月後跟進其病徵變化以測試問卷的反應性。

結果：UFS-QOL繁體中文版本的Cronbach變化以測試問卷的系數 為 0.706 至 0.937 , 顯示高度內部一致性。症狀總評分、生活素質總 評分以及各分項之組內相關系數分別為0.819（ $\mathrm{P}<0.001 ） 、 0.897$

$(\mathrm{P}<0.001)$ 及 0.721 至0.870（ $\mathrm{P}<0.001 ）$, 表示UFS-QOL繁體中文 版本的重測信度為高。此外我們亦測試UFS-QOL繁體中文版本的輻 合效度。UFS-QOL症狀總評分與其他用作量度症狀嚴重性的評估工 具結果 (PBAC和VAS) 呈正相關, 而UFS-QOL生活素質評分亦與 12 型簡短健康調查的結果呈正相關。研究結果亦顯示UFS-QOL繁體中 文版本能反映經治療後的症狀及生活質素的改變。

結論：UFS-QOL繁體中文版有效及可信，亦能有效反映治療結果， 可以用作評估子宮肌瘤患者病狀及生活素質的問卷。

symptom severity score and HRQL score, the sum of the raw scores of the related items is transformed into a final score (range, 0-100) based on a specific formula. A higher symptom severity score indicates more severe symptoms, while a higher HRQL score indicates better quality of life. The UFS-QOL has been validated, and its responsiveness was also assessed. ${ }^{8-10}$ It has been widely adopted in different studies to assess fibroid treatment outcomes ${ }^{11,12}$ and translated into multiple languages. ${ }^{13}$

The objective of this study was to produce a valid, reliable, culturally adapted Chinese version of the UFS-QOL. We believe this would serve as a useful tool to assess the impact of fibroid-related quality of life and response to treatment and facilitate future research and clinical use in the Chinese population.

\section{Methods}

\section{Translation}

We obtained approval to use the UFS-QOL from the Society of the Interventional Radiology Foundation. A forward-backward procedure was applied to translate the UFS-QOL into traditional Chinese. Two independent bilingual researchers were asked to separately produce two forward translations aiming for conceptual translation. The two translations were reviewed between the two researchers to produce a provisional draft of the Chinese UFSQOL. The provisional Chinese UFS-QOL was then back-translated to English by two other bilingual researchers who were blinded to the original questionnaire. The back-translated English version was further compared to the original questionnaire by two monolingual experts (English) with no discrepancy noted before we finalised the Chinese version of the UFS-QOL (online Supplementary Appendix).

\section{Study phase}

The study was conducted in the gynaecology clinic of a university hospital between July 2015 and July 2016. All women aged $\geq 18$ years with fibroids who understood written traditional Chinese were eligible. Women with known mental incapacity or cognitive or developmental disability were excluded. The MiniMental State Examination was performed to detect and exclude women with unreported psychiatric morbidity. Written consent was obtained.

Women were asked to fill out the Chinese UFS-QOL and Short-Form Health Survey-12 (SF-12) before consultation. The SF-12 is a 12 -item survey that assesses eight domains of quality of life (physical functioning, role limitation as a result of physical and emotional problems, bodily pain, general health, vitality, social functioning, and mental health), and it has a validated Chinese version. ${ }^{14}$ Lower SF-12 scores are associated with worse HRQL.

The participating women were assessed by gynaecologists who were blinded to the questionnaire information. Clinical and sociodemographic data including age, gravidity, parity, coexisting medical illness, menstrual status, education level, marital status, literacy, and employment status were obtained. General examinations to examine the subjects for pallor and measure their blood pressure, pulse, body weight, and height were performed. Abdominal and/or gynaecological examinations were performed to assess the uterine size and rule out other pathology. Transabdominal and/or transvaginal ultrasound were performed to measure uterine size and the number, location, and size of fibroids. Complete blood work was performed. Both the women and the attending gynaecologists were asked to grade the overall severity of symptoms on a $10-\mathrm{cm}$ visual analogue scale (VAS), with higher scores indicating more severe symptoms.

The women maintained a pictorial blood loss assessment chart (PBAC) for two menstrual cycles. The PBAC is a validated self-reporting tool with a score calculated every 4 weeks. ${ }^{15}$ A score $\geq 100$ represents heavy menstrual bleeding, and $\leq 75$ represents normal menses.

The first 60 women filled out the two questionnaires again 2 weeks later and returned them by mail to researchers. In addition, a question on perceived change in clinical condition over the past 2 weeks was asked. 
Women were offered appropriate treatment as clinically indicated. In general, tranexamic acid 500 mg 4 times daily and/or mefenamic acid $500 \mathrm{mg} 3$ times daily were prescribed for menorrhagia unless contra-indicated. Combined oral contraceptive pills were given if contraception was required and when there was no contraindication. If medical treatment failed, treatment including endometrial ablation, a levonorgestrel-containing contraceptive device, myomectomy or hysterectomy, or uterine artery embolisation (UAE) were offered.

The first half of the recruited women were followed up 6 months later. They were asked to perform PBAC, and complete blood work was performed. During follow-up, the women filled out the above questionnaires again before the gynaecologist's assessment. The women were also asked about improvement after treatment.

\section{Sample size and statistical analysis}

A sample size of five or more respondents per item has been proposed for psychometric analysis. ${ }^{16,17}$ With the UFS-QOL's total of 37 items and assuming a $20 \%$ discard rate due to incomplete filling of questionnaires, a sample size of 220 was required to adequately assess the questionnaire. ${ }^{18}$

We used SPSS (Windows version 20.0; IBM Corp, Armonk [NY], United States) for statistical analysis. The psychometric properties of the UFS-QOL were assessed following the American Psychological Association's Standards for Educational and Psychological Testing. ${ }^{19}$

\section{Reliability}

Reliability was assessed by internal consistency and test-retest correlation. Internal consistency was assessed by Cronbach's alpha coefficients, with $>0.7$ being considered acceptable. ${ }^{16,17}$ Test-retest reliability was analysed in women who reported no change to health status over the 2-week period from the first questionnaire. Test-retest reliability was assessed by intra-class correlation coefficient. Values between 0.6 and 0.8 indicate substantial agreement, and values over 0.8 indicate near-perfect agreement. ${ }^{20}$

\section{Validity}

The convergent validity of the UFS-QOL was estimated by Pearson's correlation, with participantrated symptom severity VAS score, PBAC score, and physician-rated symptom severity VAS score as well as the quality of life domains of the SF-12. For discriminant validity, the women were stratified into mild, moderate, and severe symptoms according to the women-rated symptom severity VAS scores. A score of VAS $\leq 4$ was classified as mild, while $\geq 7$ was classified as severe symptomatology. The UFS-QOL scores were compared among the three groups.

\section{Responsiveness}

Responsiveness was evaluated by comparing pre- and post-treatment scores using paired samples $t$ tests or Wilcoxon signed rank tests. The effect size (ie, change in mean score divided by the standard deviation of the baseline $)^{20}$ and standardised response mean (ie, change in mean score divided by the standard deviation of the change) were calculated. A value of 0.2 was considered as a 'small' effect, 0.5 a 'moderate' effect, and $\geq 0.8$ a 'large' effect.

\section{Results}

A total of 223 women were recruited. Their mean age was $44.8 \pm 6.0$ years (range, 28-62 years). There were multiple fibroids in $54.5 \%$ of the participants, and $51.6 \%$ of the women had uterine size $\geq 12$ weeks. Overall, $28.3 \%, 73.3 \%, 47.1 \%$, and $29.1 \%$ reported cycle irregularity, menorrhagia, dysmenorrhoea, and pressure symptoms from fibroids, respectively, while $12.1 \%$ were asymptomatic. The median UFS-QOL score at recruitment was 40.6 (interquartile range $[\mathrm{IQR}]=25.0-56.3)$ and 67.2 (IQR=48.3-83.6) for symptom severity and HRQL, respectively.

\section{Reliability}

The internal consistency and test-retest reliability values are shown in Table 1 . The Cronbach's alpha values of all subscales were $>0.7$. Fifty-one women (85\%) returned the questionnaire 2 weeks after the initial visit. All of them reported no health changes. Test-retest reliability indicated substantial to perfect agreement.

\section{Validity}

Convergent validity was assessed by the degree of

TABLE I. Internal consistency and test-retest reliability of UFSQOL subscales

\begin{tabular}{lcc}
\hline UFS-QOL & $\begin{array}{c}\text { Internal } \\
\text { consistency } \\
\text { (Cronbach's } \\
\text { alpha)* }\end{array}$ & $\begin{array}{c}\text { Test-retest } \\
\text { reliability (intra- } \\
\text { class correlation } \\
\text { coefficients)† }\end{array}$ \\
\hline Symptom severity & 0.825 & 0.819 \\
\hline Concern & 0.877 & 0.834 \\
Activities & 0.918 & 0.840 \\
Energy/mood & 0.915 & 0.823 \\
\hline Control & 0.892 & 0.870 \\
Self-consciousness & 0.706 & 0.844 \\
Sexual functioning & 0.937 & 0.721 \\
\hline
\end{tabular}

Abbreviation: UFS-QOL = Uterine Fibroid Symptom and Healthrelated Quality of Life

* $>0.70=$ satisfactory internal consistency

† $0.20=$ low; $0.21-0.40=$ fair; $0.41-0.60=$ moderate; $0.61-0.80$

= substantial; 0.8I- I = almost perfect 
correlation of the UFS-QOL symptoms severity score on the one hand with the women-rated and physician-rated VAS scores and PBAC score on the other. There was a moderate degree of correlation between the UFS-QOL and these assessment tools (Table 2).

A negative correlation was seen between the UFS-QOL symptom severity subscale and all domains of the SF-12, and a positive correlation was observed between the HRQL subscales and SF-12 domains. The energy/mood and activities subscales had the strongest correlation with the role-emotional domain of the SF-12 $(r=0.597, \mathrm{P}<0.001)$.

The UFS-QOL scores for symptomatic and asymptomatic women were significantly different across all subscales (median symptom severity score: 43.8 vs $21.9, \mathrm{P}<0.001$; median HRQL score: 79.3 vs $63.8, \mathrm{P}<0.001)$. For women with clinically palpable uterus, the scores on the control and selfconsciousness subscales were lower than those of women with smaller uterus size (median score of control subscale: 65.0 vs $75.0, \mathrm{P}=0.025$; median score of self-consciousness subscale: 67.0 vs $75.0, \mathrm{P}=0.015$ ). Women with significant anaemia (haemoglobin level
$<80 \mathrm{~g} / \mathrm{L}$ ) had lower energy and activity subscale scores (median energy score: 50.0 vs $67.9, \mathrm{P}=0.014$; median activity score: 42.9 vs $66.1, \mathrm{P}=0.013$ ) than women who were not anaemic had.

Women were classified into three groups (mild, moderate and severe symptoms) according to their symptom severity VAS score $(\leq 4,4.1-7$, and $\geq 7$ ). Higher women-rated severity score was associated with higher UFS-QOL symptom severity score, with significant differences between different severity groups. Similarly, higher women's VAS severity score was associated with lower UFS-QOL HRQL scores. The differences in UFS-QOL score among the three groups were statistically significant $(\mathrm{P}<0.001)$ for all except the mild versus moderate groups on the sexual functioning subscale (Fig).

\section{Responsiveness}

Among the 100 women being followed up, 50 received medical treatment, 21 received surgery and UAE ( 15 hysterectomies, 4 myomectomies, $2 \mathrm{UAE}$ ), and 29 did not receive any treatment. There was a significant reduction in symptom severity score and improvement in HRQL subscale scores after any

TABLE 2. Convergent validity-Pearson's correlation between UFS-QOL symptom severity subscale,VAS by women and gynaecologists, and PBACs

\begin{tabular}{|c|c|c|c|c|c|c|c|}
\hline Subscale & $\begin{array}{l}\text { Symptom } \\
\text { severity }\end{array}$ & Concern & Activities & $\begin{array}{l}\text { Energy/ } \\
\text { mood }\end{array}$ & Control & $\begin{array}{c}\text { Self- } \\
\text { consciousness }\end{array}$ & $\begin{array}{c}\text { Sexual } \\
\text { functioning }\end{array}$ \\
\hline \multicolumn{8}{|l|}{ Women's VAS scoring } \\
\hline Menorrhagia & 0.527 & -0.461 & -0.409 & -0.304 & -0.254 & -0.285 & -0.203 \\
\hline Dysmenorrhoea & 0.375 & -0.249 & -0.341 & -0.331 & -0.241 & -0.238 & -0.200 \\
\hline Pressure symptoms & 0.583 & -0.311 & -0.413 & -0.446 & -0.417 & -0.492 & -0.379 \\
\hline Overall severity & 0.627 & -0.502 & -0.533 & -0.629 & -0.584 & -0.506 & -0.396 \\
\hline \multicolumn{8}{|c|}{ Gynaecologist's VAS scoring } \\
\hline Menorrhagia & 0.458 & -0.359 & -0.368 & -0.415 & -0.377 & -0.406 & -0.318 \\
\hline Dysmenorrhoea & 0.298 & -0.409 & -0.425 & -0.392 & -0.344 & -0.371 & -0.275 \\
\hline Pressure symptoms & 0.405 & -0.182 & -0.267 & -0.246 & -0.197 & -0.200 & $-0.111 \dagger$ \\
\hline Overall severity & 0.458 & $-0.151^{*}$ & -0.297 & -0.375 & -0.318 & -0.379 & -0.299 \\
\hline PBAC scoring & 0.417 & -0.384 & -0.284 & -0.350 & -0.282 & -0.205 & -0.300 \\
\hline \multicolumn{8}{|l|}{ SF-12 subscales } \\
\hline Physical functioning & -0.402 & 0.385 & 0.476 & 0.453 & 0.412 & 0.451 & 0.348 \\
\hline Role-physical & -0.418 & 0.445 & 0.587 & 0.540 & 0.534 & 0.510 & 0.399 \\
\hline Bodily pain & -0.589 & 0.520 & 0.583 & 0.583 & 0.555 & 0.496 & 0.463 \\
\hline General health & -0.353 & 0.395 & 0.414 & 0.414 & 0.472 & 0.358 & 0.309 \\
\hline Vitality & -0.397 & 0.383 & 0.401 & 0.401 & 0.411 & 0.378 & 0.246 \\
\hline Social functioning & -0.380 & 0.433 & 0.570 & 0.505 & 0.440 & 0.440 & 0.337 \\
\hline Role-emotional & -0.482 & 0.516 & 0.597 & 0.597 & 0.492 & 0.492 & 0.467 \\
\hline Mental health & -0.435 & 0.391 & 0.410 & 0.410 & 0.440 & 0.440 & 0.444 \\
\hline \multicolumn{8}{|c|}{$\begin{array}{l}\text { Abbreviations: PBAC = pictorial blood loss assessment chart; SF- } 12=\text { Short-Form Health Survey- } 12 ; \text { UFS-QOL }=\text { Uterine Fibroid } \\
\text { Symptom and Health-related Quality of Life;VAS = visual analogue scale } \\
\text { * } P=0.02\end{array}$} \\
\hline
\end{tabular}


treatment, except on the sexual functioning subscale (Table 3). Despite the results being statistically insignificant, the sexual functioning subscale still showed a trend towards quality of life improvement with treatment. For surgically treated women, the reduction in symptom severity score ranged from 22 to 38 with a large effect size (range, 0.8-2.6).

For women reporting no improvement $(\mathrm{n}=53)$, reduction in symptom severity scores and improvement in HRQL scores were modest except for the control subscale $(\mathrm{P}=0.027)$. For those participants who reported improvement $(n=47)$, there was a significant reduction in symptom severity score and improvement in HRQL scores. The changes were significant except for the sexual functioning subscale $(\mathrm{P}=0.14)$. Women who reported improvement demonstrated greater improvement in symptom severity and all HRQL subscales by 7 to 19 points. The differences were significant for all except the energy/mood and sexual functioning subscales (Table 4).

\section{Discussion}

Fibroids are common in women, and the Chinese population is no exception. Newer treatments such as ulipristal acetate and high intensity focused ultrasound ablation can shrink fibroids to improve symptoms. ${ }^{21-24}$ Assessment of effects on quality of life is essential for evaluation of the usefulness of these modalities.

The UFS-QOL is a simple, disease-specific tool that has been used in various studies to assess treatment outcomes. The Chinese version of the UFS-QOL needs to be validated before application for clinical and research purposes because of cultural differences and language-specific concerns.
Our results showed that the Chinese UFS-QOL is a reliable tool with high internal consistency (Cronbach's alpha $>0.7$ for all subscales) and almost perfect agreement between test and retest results (intra-class correlation coefficient $>0.8$ for all except the sexual functioning subscale). These results are comparable with the original and other translated version of the UFS-QOL. ${ }^{8,13}$

The validity of the Chinese UFS-QOL was supported by moderate positive correlations between the women-rated VAS score, physician-rated VAS score, PBAC score, and UFS-QOL symptom severity

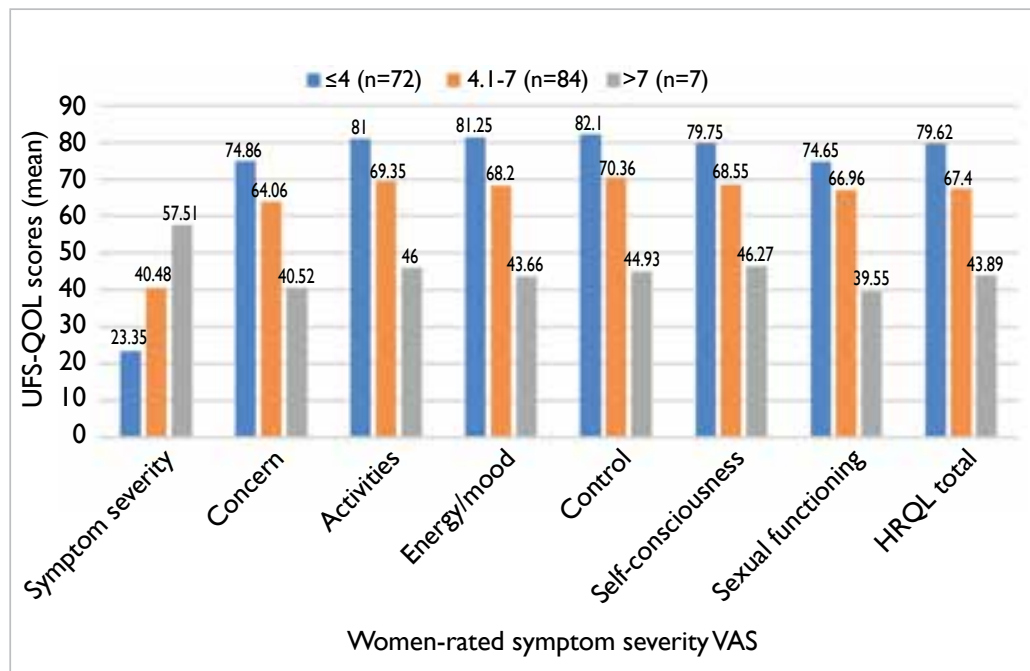

FIG. Discriminant validity comparison of women-rated symptom severity score (VAS) and UFS-QOL subscales*

Abbreviations: $\mathrm{HRQL}=$ health-related quality of life; UFS-QOL = Uterine Fibroid Symptom and Health-related Quality of Life;VAS = visual analogue scale

* Pairwise group comparison, all $\mathrm{P}<0.00 \mathrm{I}$ (except for sex function domain between mild and moderate groups).VAS: 0 least severe, 10 most severe

TABLE 3. Responsiveness of women with uterine fibroids after treatment $(n=71)$ *

\begin{tabular}{|c|c|c|c|c|c|}
\hline \multirow[t]{2}{*}{ UFS-QOL subscales } & \multicolumn{2}{|c|}{ Mean score (SD) } & \multirow{2}{*}{$\begin{array}{l}\text { Mean change in } \\
\text { score (SD) }\end{array}$} & \multirow[t]{2}{*}{ Effect size } & \multirow[t]{2}{*}{ SRM } \\
\hline & Baseline & Post-treatment & & & \\
\hline \multicolumn{6}{|l|}{ Treatment group } \\
\hline Symptom severity & $48.2(18.7)$ & $32.9(20.0)$ & $-15.3 \pm 23.9$ & 0.82 & 0.64 \\
\hline Concern & $51.0(23.2)$ & $65.4(26.1)$ & $14.4 \pm 28.0$ & 0.62 & 0.50 \\
\hline Activities & $59.0(24.4)$ & $69.0(24.4)$ & $10.1 \pm 27.8$ & 0.41 & 0.36 \\
\hline Energy/mood & $59.9(22.0)$ & $69.4(21.2)$ & $9.5 \pm 21.1$ & 0.43 & 0.45 \\
\hline Control & $62.0(24.8)$ & $73.9(21.4)$ & $11.9 \pm 23.5$ & 0.47 & 0.51 \\
\hline Self-consciousness & $61.0(25.5)$ & $70.0(22.1)$ & $8.7 \pm 27.0$ & 0.34 & 0.32 \\
\hline Sexual functioning & $55.5(35.3)$ & $61.4(34.4)$ & $6.0 \pm 39.0$ & 0.17 & 0.15 \\
\hline Total HRQL score & $58.3(20.8)$ & $68.8(20.5)$ & $10.6 \pm 22.5$ & 0.51 & 0.47 \\
\hline
\end{tabular}

Abbreviations: $\mathrm{HRQL}=$ health-related quality of life; $\mathrm{SD}=$ standard deviation; $\mathrm{SRM}=$ standardised response mean; UFS-QOL = Uterine Fibroid Symptom and Health-related Quality of Life

* There were statistically significant differences between the pretreatment and post-treatment scores for all domains except sexual functioning $(P=0.2)$ 
TABLE 4. Change in UFS-QOL scores at 6 months follow-up, by overall treatment effects

\begin{tabular}{|c|c|c|c|c|}
\hline \multirow[t]{2}{*}{ UFS-QOL domains } & \multicolumn{2}{|c|}{ Change in mean score (SD) } & \multirow{2}{*}{$\begin{array}{l}\text { Mean difference of } \\
\text { change in score }\end{array}$} & \multirow[t]{2}{*}{$P$ value } \\
\hline & No improvement $(n=53)^{\star}$ & Improved $(n=47) \dagger$ & & \\
\hline Symptom severity & $-3.7(15.9)$ & $-22.5(22.5)$ & -19.1 & $<0.001$ \\
\hline Concern & $1.7(19.8)$ & $22.8(27.6)$ & 21.1 & $<0.001$ \\
\hline Activities & $1.6(24.0)$ & $16.3(26.5)$ & 14.6 & 0.005 \\
\hline Energy/mood & $5.0(18.5)$ & $12.1(20.6)$ & 7.1 & 0.073 \\
\hline Control & $6.2(19.9)$ & $15.9(23.8)$ & 9.6 & 0.030 \\
\hline Self-consciousness & $1.3(22.5)$ & $15.1(26.9)$ & 13.8 & 0.006 \\
\hline Sexual functioning & $2.4(28.3)$ & $9.3(42.7)$ & 7.0 & 0.347 \\
\hline Total HRQL score & $3.3(17.2)$ & $15.7(22.5)$ & 12.4 & 0.002 \\
\hline
\end{tabular}

Abbreviations: HRQL = health-related quality of life; $\mathrm{SD}=$ standard deviation; UFS-QOL = Uterine Fibroid Symptom and Healthrelated Quality of Life

* No improvement group: score changes not significant for all domains except control $(P=0.027)$

$\dagger$ Improvement group: score changes significant for all domains except sexual functioning $(P=0.14)$

score (with correlation coefficients ranging 0.30.6). There was also a moderate positive correlation between the SF-12 and UFS-QOL HRQL subscale scores. The energy/mood domain of the UFS-QOL had the strongest correlation with the SF-12 roleemotion domain $(r=0.597)$. Women with larger uterus size scored lower in the control and selfconsciousness domains, and those with significant anaemia also had lower energy and activity scores. These results reflected the ability of the Chinese UFS-QOL to assess the underlying constructs.

The Chinese UFS-QOL also demonstrated responsiveness towards change in women who received treatment. The mean change in subscale scores ranged from 6 to 15 points at 6 months posttreatment. The changes were most pronounced for women who received surgery (myomectomy or hysterectomy), who had a mean score increase from 22 to 39 and an effect size of $\geq 0.8$ for all subscales. Similar findings were also reported in a previous study. $^{23}$ In addition, larger score changes was observed in women who received surgery compared with medical treatment, an effect that has also been shown in other studies. ${ }^{24}$ The Chinese UFS-QOL was able to discriminate between women who reported that their treatment was effective compared with those who did not. Although there were mean increases of 7 points in both the energy/mood and sexual functioning subscales, they did not reach statistical significance. This might be explained by the fact that mood and sexual satisfaction could be affected by multiple factors other than fibroid symptoms alone. Improvement in fibroid-related symptoms alone might not result in dramatic changes in these aspects of quality of life.

\section{Strengths and limitations}

Our study sample included a wide range of Acquisition of data: SY Yeung, SM Law, JWK Kwok. disease severities and a broad symptom spectrum, which allows generalisation of the findings to the community of women with fibroids. Another strength is that the responsiveness of the UFS-QOL was evaluated, which allows its use to assess treatment effects. However, the study has a few limitations. The minimal important difference, ie, the smallest clinically significant change in score large enough to implicate treatment, was not assessed. In addition, the majority of women who returned for follow-up received either medical treatment or hysterectomy, whereas few underwent myomectomy or UAE. Further studies may be required to address these issues. Finally, there are two forms of written Chinese characters (traditional and simplified). Because the Chinese UFS-QOL is a selfadministered questionnaire written in traditional Chinese, application to women who can read only simplified Chinese characters may be limited.

\section{Conclusion}

Our study showed that the Chinese version of UFS-QOL is comparable to the original and other translated version of this questionnaire in terms of reliability, validity, ${ }^{8,9,13}$ and responsiveness. ${ }^{10}$ In conclusion, the Chinese version of the UFS-QOL is a reliable, valid tool for the assessment of symptom severity and HRQL. It can be used to evaluate efficacy and treatment effects on fibroids in women in the future.

\section{Author contributions}

All authors had full access to the data, contributed to the study, approved the final version for publication, and take responsibility for its accuracy and integrity. 
Analysis or interpretation of data: SY Yeung, JWK Kwok. Drafting of the article: SY Yeung.

Critical revision for important intellectual content: SM Law, SSC Chan, JPW Chung.

\section{Acknowledgement}

The authors thank Dr Linda WY Fung for performing the forward translation, Dr Alyssa SW Wong for the backward translation, Professor Sonia Grover and Dr Sotirios Saravelos for evaluating the final English version against the original questionnaire.

\section{Conflicts of interest}

As an editor of the journal, JPW Chung was not involved in the peer review process of the article. Other authors have disclosed no conflict of interest.

\section{Declaration}

The preliminary results of part of this study (reliability and validity) have been presented during an oral presentation session at the 25th Asian \& Oceanic Congress of Obstetrics \& Gynaecology in Hong Kong, June 2017.

\section{Funding/support}

This research received no specific grant from any funding agency in the public, commercial, or not-for-profit sectors.

\section{Ethics approval}

Ethics approval was obtained in April 2015 from the Joint Chinese University of Hong Kong-New Territories East Cluster Clinical Research Ethics Committee (CREC Ref 2015.085).

\section{References}

1. Stewart EA, Cookson CL, Gandolfo RA, Schulze-Rath R. Epidemiology of uterine fibroids: a systematic review. BJOG 2017;124:1501-12.

2. Okolo S. Incidence, aetiology and epidemiology of uterine fibroids. Best Pract Res Clin Obstet Gynaecol 2008;22:57188.

3. Vercellini P, Vendola N, Ragni G, Trespidi L, Oldani S, Crosignani PG. Abnormal uterine bleeding associated with iron-deficiency anemia. Etiology and role of hysteroscopy. J Reprod Med 1993;38:502-4.

4. Emanuel MH, Verdel MJ, Stas H, Wamsteker K, Lammes FB. An audit of true prevalence of intra-uterine pathology: the hysteroscopical findings controlled for patient selection in 1202 patients with abnormal uterine bleeding. Gynaecological Endoscopy 1995;4:237-42.

5. Ando K, Morita S, Higashi T, et al. Health-related quality of life among Japanese women with iron-deficiency anemia. Qual Life Res 2006;15:1559-63.

6. Dancz CE, Kadam P, Li C, Nagata K, Özel B. The relationship between uterine leiomyomata and pelvic floor symptoms. Int Urogynecol J 2014;25:241-8.

7. Moshesh M, Olshan AF, Saldana T, Baird D. Examining the relationship between uterine fibroids and dyspareunia among premenopausal women in the United States. J Sex Med 2014;11:800-8.

8. Spies JB, Coyne K, Guaou Guaou N, Boyle D, Skyrnarz-
Murphy K, Gonzalves SM. The UFS-QOL, a new disease-specific symptom and health-related quality of life questionnaire for leiomyomata. Obstet Gynecol 2002;99:290-300.

9. Coyne KS, Margolis MK, Bradley LD, Guido R, Maxwell GL, Spies JB. Further validation of the uterine fibroid symptom and quality-of-life questionnaire. Value Health 2012;15:135-42.

10. Harding G, Coyne KS, Thompson CL, Spies JB. The responsiveness of the uterine fibroid symptom and healthrelated quality of life questionnaire (UFS-QOL). Health Qual Life Outcomes 2008;6:99.

11. Smith WJ, Upton E, Shuster EJ, Klein AJ, Schwartz ML. Patient satisfaction and disease specific quality of life after uterine artery embolization. Am J Obstet Gynecol 2004;190:1697-703.

12. Olive DL. Sustained relief of leiomyoma symptoms by using focused ultrasound surgery. Obstet Gynecol 2008;111:775.

13. Oliveira Brito LG, Malzone-Lott DA, Sandoval Fagundes MF, et al. Translation and validation of the Uterine Fibroid Symptom and Quality of Life (UFS-QOL) questionnaire for the Brazilian Portuguese language. Sao Paulo Med J 2017;135:107-15.

14. Lam CL, Tse EY, Gandek B. Is the standard SF-12 health survey valid and equivalent for a Chinese population? Qual Life Res 2005;14:539-47.

15. Higham JM, O'Brien PM, Shaw RW. Assessment of menstrual blood loss using a pictorial chart. Br J Obstet Gynaecol 1990;97:734-9.

16. Bryant FB, Yarnold PR. Principal components analysis and exploratory and confirmatory factor analysis. In: Grimm LG, Yarnold PR, editors. Reading and Understanding Multivariate Statistics. American Psychological Association, Washington DC; 1995: 99-136.

17. Gorsuch RL. Factor Analysis. 2nd ed. Hillsdale, NJ: Lawrence Erlbaum Associates; 1983.

18. Machin D, Campbell MJ, Tan SB, Tan SH. Sample Size Tables for Clinical Studies, 3rd ed. Chichester, UK: WileyBlackwell; 2009.

19. American Educational Research Association, American Psychological Association, National Council on Measurement in Education; Joint Committee on Standards for Educational and Psychological Testing. Standards for educational and psychological testing. Washington, DC: American Educational Research Association; 1999.

20. Cohen J. Statistical power analysis for the behavioral sciences. Hillsdale, NJ: Lawrence Erlbaum Associates; 1988.

21. Donnez J, Hudecek R, Donnez O, et al. Efficacy and safety of repeated use of ulipristal acetate in uterine fibroids. Fertil Steril 2015;103:519-27.e3.

22. Donnez J, Donnez O, Matule D, et al. Long-term medical management of uterine fibroids with ulipristal acetate. Fertil Steril 2016;105:165-73.e4.

23. Froeling V, Meckelburg K, Schreiter NF, et al. Outcome of uterine artery embolization versus MR-guided highintensity focused ultrasound treatment for uterine fibroids: long-term results. Eur J Radiol 2013;82:2265-9.

24. Chan SS, Cheung RY, Lai BP, Lee LL, Choy KW, Chung TK. Responsiveness of the Pelvic Floor Distress Inventory and Pelvic Floor Impact Questionnaire in women undergoing treatment for pelvic floor disorders. Int Urogynecol J 2013;24:213-21. 